\title{
The influence of palatal harvesting technique on the donor site vascular injury: A split-mouth comparative cadaver study
}

\author{
Lorenzo Tavelli $^{1}$ (D) | Shayan Barootchi ${ }^{1}$ (D) | Sharon S. Namazi ${ }^{2} \quad$ Hsun-Liang Chan ${ }^{1}$ (iD | \\ David Brzezinski $^{2}$ | Theodora Danciu $^{1,3}$ | Hom-Lay Wang ${ }^{1}$ (iD
}

${ }^{1}$ Department of Periodontics \& Oral

Medicine, University of Michigan School of

Dentistry, Ann Arbor, MI

${ }^{2}$ Division of Anatomy, Department of Surgery, University of Michigan Medical School, Ann Arbor, MI

${ }^{3}$ Department of Oral and Maxillofacial Pathology, University of Michigan School of Dentistry, Ann Arbor, MI

Correspondence

Hom-Lay Wang, DDS, MS, PhD, Department of Periodontics and Oral Medicine, University of Michigan School of Dentistry, 1011 North University Avenue, Ann Arbor, MI 481091078.

Email:homlay@umich.edu

\begin{abstract}
Background: The aim of this study was to evaluate the influence of two harvesting approaches on the donor site vascular injury.

Methods: A split-mouth cadaver study was designed on 21 fresh donor heads. Every hemi-palate was assigned to receive the trap-door harvesting technique (TDT) or the epithelialized free gingival graft harvesting technique (FGGT). A soft tissue graft was harvested from each side for histology analyses. Betadine solution was used to inject the external carotid artery and a collagen sponge was positioned over the harvested area to compare the amount of "leakage."

Results: The mean leakage observed was $16.56 \pm 3.01 \mu \mathrm{L}$ in the FGGT-harvested sites, and $69.21 \pm 7.08 \mu \mathrm{L}$ for the TDT group, a ratio of $4.18(P<0.01)$. Regression analyses demonstrated a trend for more leakage at thinner palatal sites for the FGGT group $(P=0.09)$, and a statistically significant correlation for the TDT-harvest sites $(P=0.02)$. Additionally, a shallow palatal vault height $(\mathrm{PVH})$ was associated with a higher leakage in both harvesting groups $(P=0.02)$. The histomorphometric analyses revealed that grafts harvested with TDT exhibited a significantly higher mean number of medium ( $\varnothing=0.1$ to $0.5 \mathrm{~mm}, P=0.03$ ), and large vessels $(\varnothing \geq 0.5 \mathrm{~mm}, P=0.02$ ).

Conclusions: Within the limitations of the present research, the TDT resulted in a significantly higher leakage than the FGGT, which was also correlated with the histology analyses where a greater number of medium and large vessels were observed in the harvested grafts.
\end{abstract}

\section{K E Y W O R D S}

bleeding, blood loss, cadaver, hemorrhage, histology, surgical flaps

\section{1 | INTRODUCTION}

Soft tissue augmentation procedures are routinely performed for the treatment of mucogingival deformities, such as gingival recessions, inadequate keratinized mucosa, thin gingival biotype, and for peri-implant soft tissue reconstruction. ${ }^{1,2}$

The introduction of microsurgical approaches using high magnification with microsurgical instruments has improved the predictability of root coverage procedures. ${ }^{3}$ Similarly, several graft materials such as the xenogeneic and acellular dermal matrices, have been used for avoiding a second surgical site and reducing patient morbidity. ${ }^{4,5}$ Nevertheless, these materials have achieved less ideal clinical outcomes when compared to autogenous connective tissue graft (CTG) or the free gingival graft harvesting technique (FGGT) ${ }^{5-7}$ This may be because of the lack of cellular components, characteristic 
of graft substitutes, ${ }^{8}$ as well as the associated higher shrinkage over time. ${ }^{9}$ On the other hand, CTG acts as a biological filler to enhance the flap adaptation to the root surface and to increase gingival thickness. ${ }^{10}$ In a systematic review and meta-analysis, Thoma et al. concluded that autogenous grafts (either CTG or FGGT) were the most effective technique in augmenting keratinized mucosa at implant sites, ${ }^{7}$ a crucial factor for maintaining peri-implant health. ${ }^{11}$

Clinicians have explored different approaches for harvesting a CTG from the palate, while aiming at minimizing patient morbidity and complications, including intra-surgical and post-surgical excessive bleeding, flap dehiscence and donor site infections. ${ }^{12-16}$ Palatal harvesting was first introduced in the late $60^{\prime} \mathrm{s}$ as an epithelialized free gingival graft (FGG) that healed by secondary intention. ${ }^{17}$ Afterward, Edel proposed the "trap-door" harvesting technique (TDT) that included one horizontal and two vertical incisions, creating a palatal flap that is repositioned after harvesting a CTG, to achieve a complete wound closure. ${ }^{18}$ Langer \& Langer introduced an approach that allowed for harvesting a CTG containing a small band of epithelium. ${ }^{19}$ Several modifications were subsequently proposed to the "trap-door" approaches..$^{20,21}$ In an attempt to avoid vertical incisions, a palatal harvesting technique with a single horizontal incision was also described. ${ }^{22,23}$ The introduction of the single incision technique ensured a consistent thickness of the flap and the harvesting of a "deeper" CTG that tends to include the periosteum layer. ${ }^{23}$ Nevertheless, among the disadvantages of the mentioned techniques, over-thinning of the palatal flap that leads to wound sloughing and patient discomfort, has often been encountered. ${ }^{15,24}$ Particularly, it has been suggested that, when the palatal fibromucosa thickness is limited, these techniques should be avoided. ${ }^{15,25}$ CTG harvested with the mentioned approaches is commonly referred to as sub-epithelial CTG (SCTG).

More recently, Zucchelli and coworkers ${ }^{15}$ proposed the extraoral de-epithelialization of the FGG to obtain a CTG (DeCTG), demonstrating that healing by secondary intention is not associated with increased post-operative discomfort. ${ }^{15}$ The authors suggested that the FGGT approach can be performed regardless of fibromucosa thickness and that the quality of the DeCTG may be superior than a SCTG which is harvested deeper and contains less lamina propria and more fatty and glandular tissue. ${ }^{15,26}$ Despite its clinical significance remains unknown, it has been shown that DeCTG may include epithelial remnants. ${ }^{27}$

In the literature, however, whether one harvesting technique is superior to the other, remains controversial and their comparison has always been investigated in terms of postoperative morbidity or root coverage outcomes. ${ }^{13,15,28}$ It is reasonable to assume that the harvesting technique also affects the amount of intraoperative bleeding, which is a frequent event that complicates the CTG harvesting and hemostasis of the donor site. ${ }^{12,29}$ Although several cadaver studies were performed to evaluate the course of the greater palatine artery and establish the anatomical limits for soft tissue harvesting, ${ }^{30,31}$ the correlation between the palatal vascular injury and the area of CTG harvesting (whether superficial or deep, depending on the technique) has not yet been evaluated in clinical studies, mainly for ethical reasons. Therefore, the aim of this study was to evaluate the influence of two harvesting techniques (TDT versus FGGT) to the vasculature injury of the palate in a cadaver model.

\section{2 | MATERIALS AND METHODS}

\section{1 | Study design}

The study consisted of 21 un-embalmed donor heads in a split-mouth design (42 sites in total), such that each hemipalate was randomly assigned to either receive the TDT, or the epithelialized FGGT.

\section{2 | Study specimens}

The specimens (age: 47 to 78 years) were donated to the Department of Periodontics and Oral Medicine, University of Michigan. All donor heads were preserved in a controlled $-20^{\circ} \mathrm{C}$ environment, without fixation in formalin to avoid minimal tissue structural changes. Only immediately prior to utilization in the study were all specimens thawed to room temperature.

The following inclusion criteria were used for selection of the specimens for the study: (1) the presence of maxillary premolars on both sides, and (2) no GRs or GR $\leq 3 \mathrm{~mm}$ on the mid-palatal side of the maxillary premolars. However, presence of any of the following factors led to the exclusion of the specimens from the study: (1) GR $>3 \mathrm{~mm}$ on the midpalatal side of at least one maxillary premolar; and (2) probing depth $>4 \mathrm{~mm}$ on the mid-palatal side of at least one maxillary premolar.

\section{$2.3 \mid$ Clinical measurements}

The following clinical measurements were made before the surgery (baseline) using a periodontal probe*:

- Recession depth at baseline: Measured from the cementoenamel junction (CEJ) to the gingival margin at the mid palatal site of the maxillary premolars.

- Palatal thickness (PT): Measured $5 \mathrm{~mm}$ apical to the gingival margin at the mesio-palatal side of first maxillary premolar, between the two maxillary premolars and at the disto-palatal side of the second maxillary premolar with an

* PCP UNC 15, Hu-Friedy, Chicago, IL 


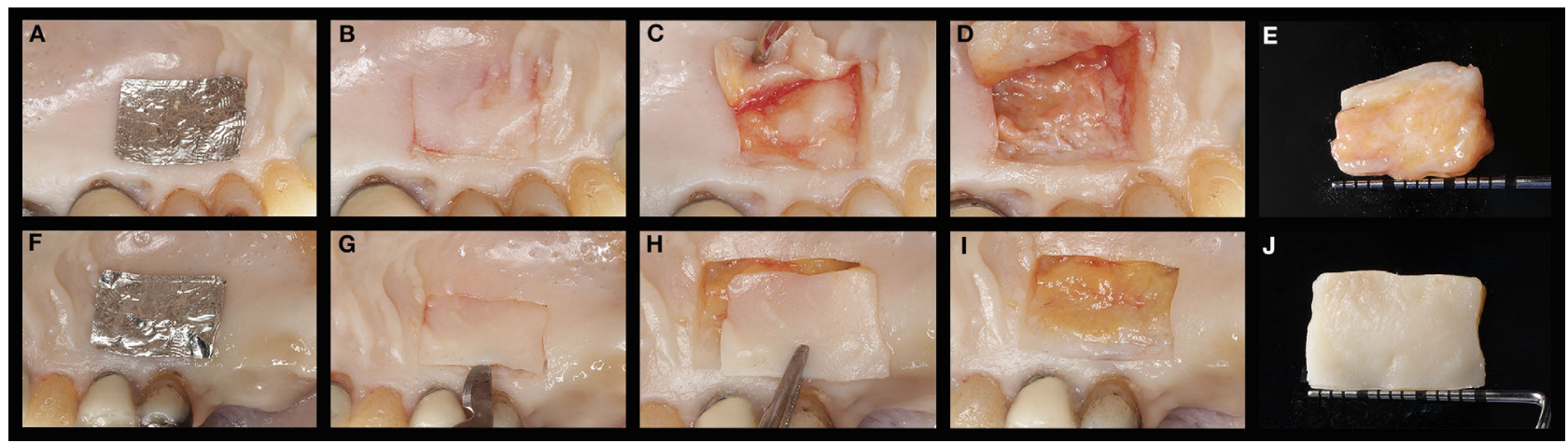

F I G U R E 1 Trap-door harvesting technique (A-E) and epithelialized gingival graft harvesting technique (F-J). (A) Foil used for determining the harvesting size; (B) incisions; (C) palatal flap elevation; (D) donor site after the harvesting of the connective tissue graft; (E) connective tissue graft; (F) foil used for determining the harvesting size; (G) incisions; (H) epithelialized gingival graft harvested; (I) donor site after the harvesting; (J) epithelialized gingival graft

injection needle perpendicular to the palatal mucosa. Then, a silicon stop was position over the mucosal surface and fixed with some drops of cyanoacrylate tissue glue.* Once removed, the distance between the silicon stop and the needle tip was measured using a digital caliper with $0.01 \mathrm{~mm}$ of accuracy. PT was calculated as the average of the three repeated measurements.

- Palatal vault height (PVH): Measured vertically from the CEJ of the maxillary premolars to the sagittal line of the palate as described by Klosek and Rungruang. ${ }^{32}$

\section{4 | Randomization}

After verification of the inclusion criteria on both hemipalates, the right and left sides were randomly assigned to either the FGGT or the TDT group using a computergenerated list. ${ }^{\dagger}$

\section{5 | Surgical procedure}

Each harvesting procedure was performed by the same provider (L.T.). PT was measured before the palatal harvesting to confirmed that a PT of at least $3 \mathrm{~mm}$ was present in the premolar area. The surgical technique performed for the TDT group was a modification of the approach described by Edel. ${ }^{18}$ Briefly, one horizontal incision of $15 \mathrm{~mm}$ was traced using a $15 \mathrm{C}$ blade at $2 \mathrm{~mm}$ apical to the gingival margin of the maxillary premolars. Two vertical releasing incisions were performed at the end of the horizontal incisions and extended apically for $8 \mathrm{~mm}$ (a foil template was used for guidance). The palatal flap was reflected in split-thickness in order to maintain a 1-mm uniform thickness. Next, the horizontal and vertical incisions were traced again with the blade perpendicular to the underlying bone and then the blade was used parallel

* PeriAcryl, Salvin Dental, Charlotte, NC.

${ }^{\dagger}$ Excel, Microsoft, Redmond, WA. to the external surface for harvesting a 1 to $2 \mathrm{~mm}$ thickness CTG. The periosteum was not included in the graft and was left in situ (Figures 1A through 1E).

In the FGGT group, the harvesting approach was performed as described by Zucchelli et al. ${ }^{15}$ Briefly, the graft dimensions were outlined using a foil template $(15 \mathrm{~mm}$ in length and $8 \mathrm{~mm}$ in height). A coronal horizontal incision was placed using a $15 \mathrm{C}$ blade at $2 \mathrm{~mm}$ apical to the gingival margin of the maxillary premolars followed by two vertical incisions perpendicular to the horizontal incision. Next, the blade was moved perpendicular to the palate until a depth of 1 to $2 \mathrm{~mm}$ was achieved. Afterwards, the blade was re-positioned parallel to the superficial surface to harvest the graft from the palatal site (Figures 1F through 1J).

\subsection{Evaluation of the leakage from the palatal donor site}

After the harvesting procedure, the external carotid artery was identified in the carotid triangle and the vessel was injected with $20 \mathrm{cc}$ of anticoagulant solution. ${ }^{\star}$ Next, air was blown into the vessels to dry the specimens and the donor heads were positioned in an upright posture using a standardized head-holding device to remove any remnants of the injected solution. ${ }^{33}$ Next to inject into the identified vessel, a betadine solution was used by an examiner (S.H.) who was calibrated prior to the start of the experiment by performing the vascular dissections and injections on four hemipalates (each twice) with at least 30 minutes separation. After the first evidence of a leakage of the solution from the harvested site, a pretrimmed, standard sized $(15 \times 8 \mathrm{~mm})$ collagen sponge ${ }^{\S}$ was lightly positioned over the donor site for 90 seconds to absorb the extravasated solution. The weight of the sponge was registered using a calibrated scale (with an accuracy of $0.0001 \mathrm{~g}$ ),

\footnotetext{
${ }^{\ddagger}$ Pre-injection fluid, Trinity Fluids, LLC, Lapeer, MI.

$\S$ CollaTape, Zimmer Biomet, Palm Beach Gardens, FL.
} 

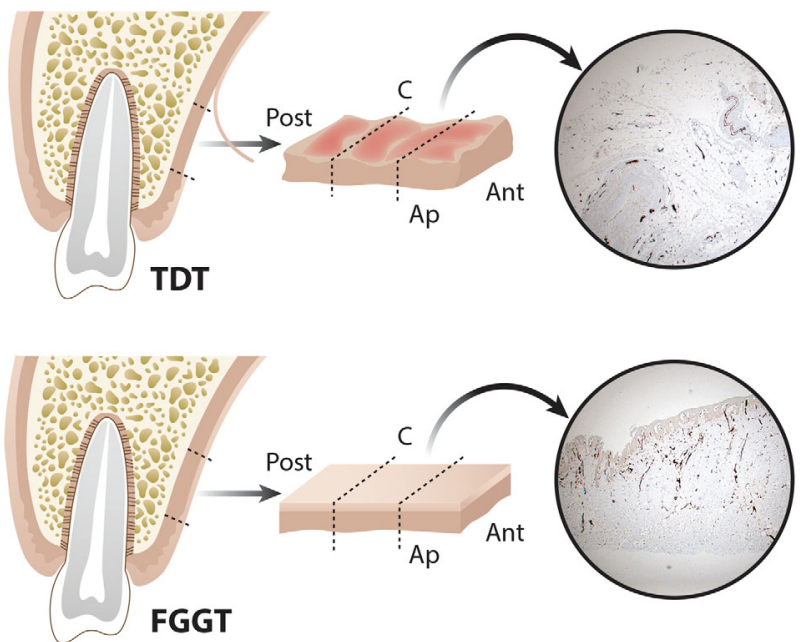

F I G U R E 2 Schematic illustration showing the method of harvesting, sectioning and analysis of the soft tissue grafts in the two groups. TDT: trap-door harvesting technique; FGGT: free gingival graft harvesting technique; Ant: anterior; Post: posterior; C: coronal; Ap: apical

before and after the placement on the donor site to measure the difference in weight (in grams). Next, the weighted measurements were converted to $\mu \mathrm{L}$ using a pre-determined formula based on a linear regression of the known solution weighs and the respective volume of the injected solution in vitro. The equation is:

$$
y=\frac{x-0.003}{0.0009}
$$

Whereas $\mathrm{x}$ denotes the weighted measurement in grams, and $y$ denotes the amount of absorbed solution by the sponge in micro-liters $(\mu \mathrm{L})$. Thus, for the purposes of the current investigation, "leakage" was considered as the amount of solution $(\mu \mathrm{L})$ that exited from of the harvested area in 90 seconds.

\section{7 | Sampling and histologic processing}

The formalin-fixed samples were processed and imbedded in paraffin and sectioned at a thickness of $0.4 \mu \mathrm{m}$ at approximately every $5 \mathrm{~mm}$ from the anterior (distal to the canine and mesial to the first premolar area) to posterior (distal to the second premolar/mesial to the first molar area) direction (Figure 2). Four to five sections were available for each specimen. Sections were either stained with hematoxylineosin or submitted for CD31 immunohistochemistry (IHC) at the University of Michigan Health System, Department of Pathology, Immunohistochemistry Laboratory. After deparaffinization and antigen-retrieval, CD31 immunostaining was performed using a mouse monoclonal anti-human antibody (CD31, clone: JC70A*) at a concentration of 1:100. IHC specimens were viewed using a E800 microscope ${ }^{\dagger}$ with a $2 \times$ objective; images were captured using a CoolSNAP EZ camera $^{\ddagger}$ and saved using a software ${ }^{\S}$ (Figure 3). CD31 expression was evaluated on the saved images, using sections 1 (anterior), 3 (middle), and when available 5 (posterior); if not available, the fourth section was used instead (Figure 4).

\section{8 | Histomorphometric analysis}

Each section was further divided into equally divided three areas apicocoronally using a specified software. ${ }^{\text {I[34 }}$ All vessels in the corresponding sections were counted and a distinct number was obtained for the coronal, medial and apical third of each section. In addition, the vessels were arbitrarily defined and identified based on their diameter as followed: $\leq 0.1 \mathrm{~mm}$ small vessels, 0.1 to $0.5 \mathrm{~mm}$ medium vessels, and $\geq 0.5 \mathrm{~mm}$ large vessels.

\subsection{Statistical analysis}

All recorded data was entered into a spread sheet and checked for entry errors. Means and standard deviations were computed for the continuous outcomes of the leakage results for both groups. For statistical comparison of the obtained results (means of both groups), independent t-test was utilized and a threshold of 0.05 was set for statistical significance. Additionally, regression analyses were performed to assess the correlation between the recorded leakage among both groups, and the recorded PVH measurements. All analyses were performed using Rstudio for Macintosh ${ }^{\#}$ by an author with expertise in statistical analyses (S.B.).

\section{3 | RESULTS}

The TDT and FGGT were randomly performed in 42 sites in 21 un-embalmed donor heads. The average PT was $4.11 \pm 0.85$ and $4.38 \pm 0.80$ for the TDT and the FGGT groups, respectively $(P=0.33)$, whereas the grafts obtained from the TDT and FGGT (without de-epithelialization) were $1.47 \pm 0.18$ and $1.41 \pm 0.23$, respectively $(P=0.79)$.

\footnotetext{
* Dako; Agilent, Santa Clara, CA.

${ }^{\dagger}$ Nikon Instruments Inc., Melville, NY.

$\ddagger$ Photometrics, Tucson, AZ.

$\S$ NIS-Elements Advanced, Nikon Corporation, Tokyo, Japan.

II Image J, Image Tool 3.0 software program, Department of Dental Diagnostics Science, University of Texas Health Science Center.

\# Rstudio Version 1.1.383, RStudio, Inc., MA
} 
Trap-door harvesting technique (TDT)

H\&E
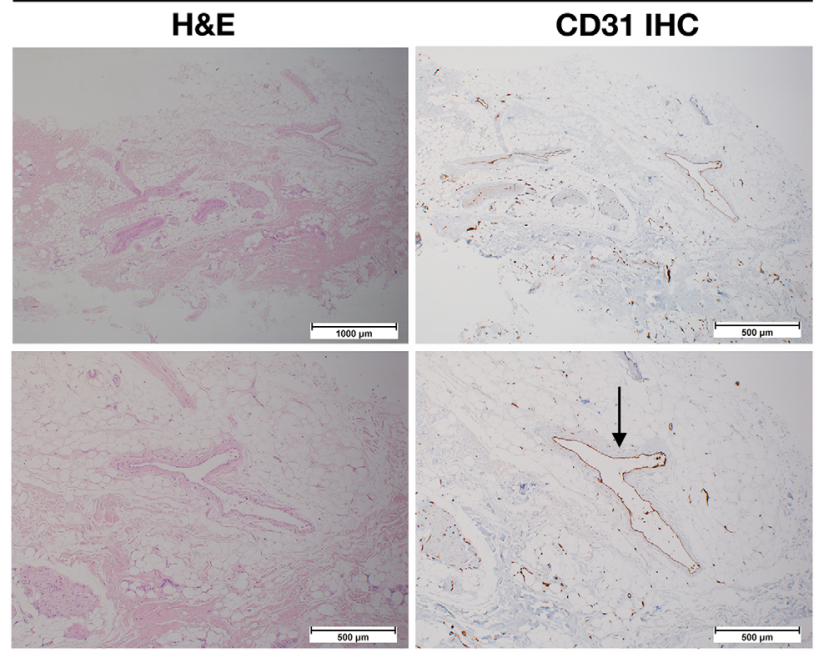

Free gingival graft harvesting technique (FGGT)

H\&E

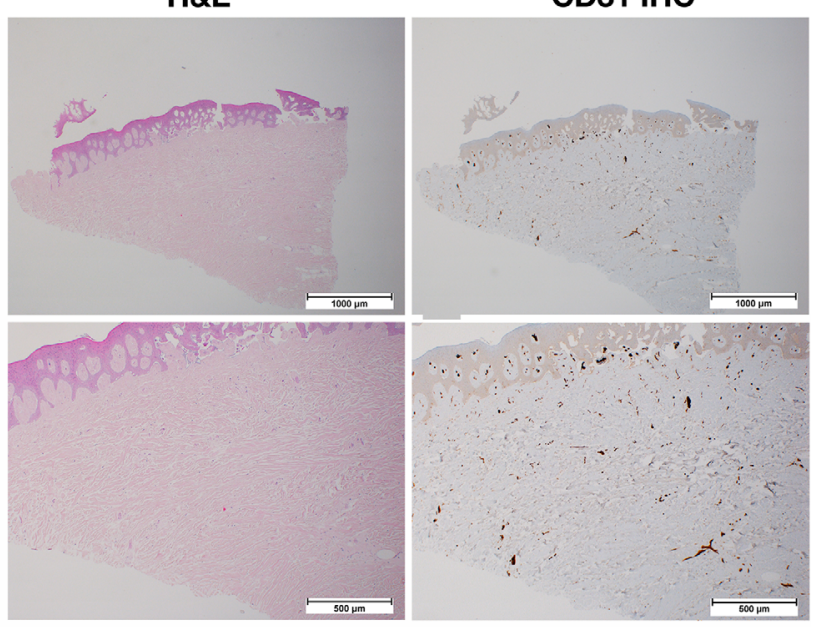

F I G U R E 3 Histological analysis from a single head comparing tissue architecture in the trap-door (TDT) to free gingival graft harvesting technique (FGGT). CD 31 immunohistochemistry highlights vessel density in the respective specimens. Note large vessel diameter present in the TDT specimen (arrow). The most posterior palatal sections were selected for both techniques (top images: $2 \times$, lower images: $4 \times$ )

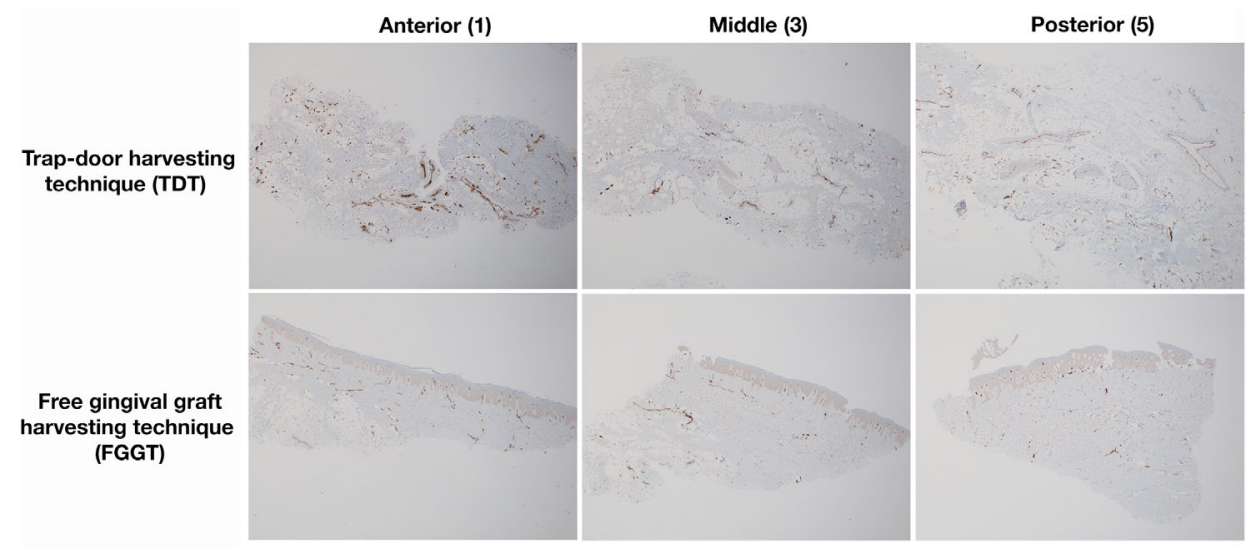

F I G U R E 4 CD 31 immunohistochemistry images from anterior to posterior palatal grafts highlighting blood vessel density and used for quantitative analysis. Five sections were available for review for this head (anterior: 1, middle: 3 and posterior: 5) (2× images)

\section{1 | Clinical measurements of the leakage}

The average leakage was $69.21 \pm 7.08 \mu \mathrm{L}$ in the TDT group, and $16.56 \pm 3.01 \mu \mathrm{L}$ in the FGGT group. This difference was statistically significant $(P<0.01)$ and lead to a ratio of 4.18 (computed as the mean leakage of the TDT over the FGGT group) (Figure 5). Regression analyses demonstrated a trend for more leakage at thinner palatal sites for the FGGT group $(P=0.09)$, and a statistically significant correlation between thinner palatal sites and increase leakage at the TDT-harvest sites $(P=0.02)$. Additionally, a shallow PVH was associated with a higher leakage in both harvesting groups $(P=0.02)$.

\section{2 | Histomorphometric results}

Although the mean total number of vessels $(P=0.44)$ and small vessels $(P=0.39)$ showed no statistically significant differences between the two techniques, the TDT exhibited a significantly higher mean number of medium $(P=0.03)$, and large vessels ( $\varnothing \geq 0.5 \mathrm{~mm}, P=0.02$ ) (Figure 3).

Posterior sections exhibited a significant greater number of medium and large vessels than anterior and middle sections in both groups $(P=0.02$ for TDT and $P=0.23$ for FGGT) (Figure 4).

When the coronal-thirds, medium-thirds, and apical-thirds of each section were considered, a significantly higher number of small vessels was noted in the coronal area for each group ( $P$ value $<0.001)$, whereas a greater number of medium and large vessels were found in the apical third compared to the medium and coronal areas in both groups $(P$ value $<0.01)$. The overall number of vessels was greater in the coronal third than middle and apical third in the FGGT group $(P$ value $<0.05)$, whereas no differences were found in the 


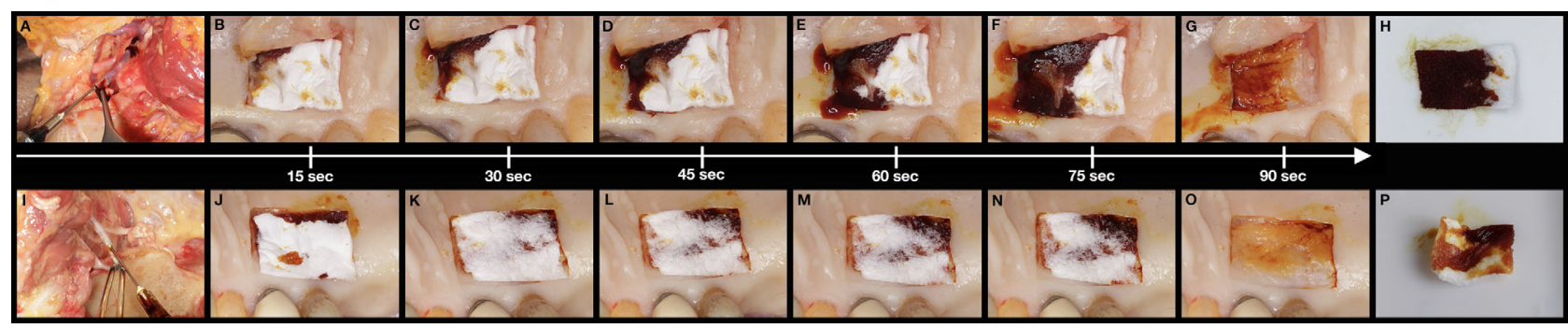

F I G U R E 5 Series of pictures showing the leakage from the donor site every 15 seconds following trap-door harvesting technique (A-H) or epithelialized gingival graft harvesting technique (I-P). Pictures A and I show the injection of betadine solution in the external carotid artery. Pictures $\mathrm{H}$ and $\mathrm{P}$ illustrates the collagen sponges after being positioned for 90 seconds in the palatal donor sites. Note that the primary flap of the trap-door harvesting technique was reflected and apically sutured for photographic purposes

T A B L E 1 Histomorphometric analysis of the specimens divided by section and site

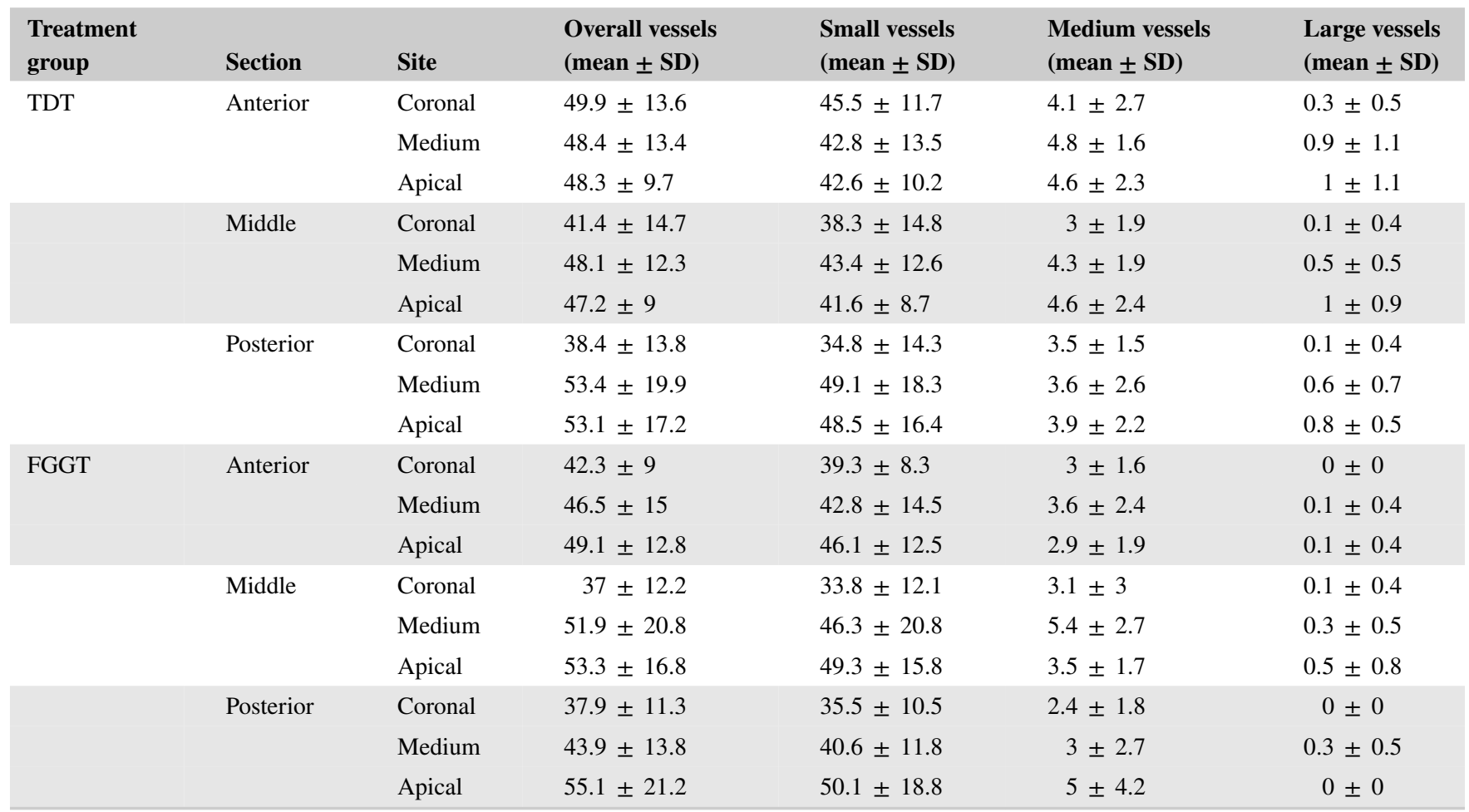

FGGT, free gingival graft harvesting technique; TDT, Trap-door harvesting technique.

TDT group $(P>0.05)$. Table 1 displays the histomorphometric results in the TDT and FGGT groups.

\section{4 | DISCUSSION}

Previous investigations comparing different harvesting approaches have shown that FGGT has more complications and higher patient morbidity rates than the TDT and single incision harvesting technique. ${ }^{13,28,35}$ However, when flap dehiscence occurs, a greater analgesic medication intake was observed compared to FGGT technique. ${ }^{15}$ It has been speculated that the higher patient morbidity associated with FGGT $^{13,28,35}$ may relate to variability in graft dimension, the removal of the periosteum (with the graft harvested too deep) and the lack of protection on the donor site. ${ }^{15}$ Indeed, it has been demonstrated that the corono-apical dimension of the graft and the residual soft tissue thickness over the bone has a significant impact on the experienced post-operative pain. ${ }^{15,36}$ Recent trials demonstrated that patient's morbidity following FGGT can be highly minimized by applying protective dressings or materials that enhance the palatal wound healing. ${ }^{16,37-39}$ Harvesting a graft from the superficial palate, thus, avoiding larger blood vessels and nerves in deeper layers has also been considered as one of the main advantages of the FGGT. ${ }^{15,40}$ Severing larger vessels and the associated prolonged intrasurgical bleeding not only complicates the harvesting and the hemostasis of the donor 
site, ${ }^{12}$ but can also negatively affect the normal stages of healing ${ }^{29}$ and cause more post-operative pain. ${ }^{15}$

To the best of our knowledge, this is the first study investigating the influence of harvesting techniques on the injury to the palatal vasculature. The study design allowed us to evaluate the injury of the vessels both in terms of leakage from the donor site and also in terms of diameters of the vessels severed by performing histological analysis, which would not have been feasible in a live human clinical study. Our results showed that the TDT had 4-fold more fluid leakage, suggesting a significantly more vasculature damage. Previous studies had reported the incidence of prolonged immediate bleeding, ranging from $11 \%$ to $25 \%$ of patients when FGGT was performed ${ }^{28,29}$ and up to $33 \%$ for the TDT approach, ${ }^{28}$ suggesting a correlation between the depth of the incisions (and the harvesting) and the bleeding. Additionally, our histological analyses seemed to correlate with the leakage findings, as a significantly greater number of medium and large vessels were found in the grafts harvested with the TDT technique. Although it cannot be directly implied that severing a smaller number of large vessels may cause more bleeding than damaging a larger number of smaller vessels, the number of small vessels among both groups was found to be similar. Therefore, it can be concluded that the greater leakage observed for the TDT technique can most likely be related to the injury caused by severing the medium and larger vessels during the harvesting procedure.

Additionally, we found that palatal thickness was a factor significantly correlated with increased leakage in only the TDT group. These results have to be interpreted with caution as our findings are based on a cadaver model, where the soft tissue typically undergoes a dehydration process which may affect the thickness of the palatal fibromucosa. ${ }^{41,42}$ Nevertheless, it can be speculated that palatal thickness may have a small influence on the leakage following FGGT because the graft is harvested from the superficial palate (where the vessels are smaller). This may not hold true for the TDT where the thinner the palate, the deeper the graft will be harvested from (approximating to the periosteum) which may lead to severing larger vessels.

The palatal soft tissue thickness has been shown to be highly associated with patient morbidity. ${ }^{15,24,36}$ Zucchelli et al. found a greater analgesic consumption in patients with lower residual soft tissue thickness over the bone after the harvesting procedure. ${ }^{15}$ The same finding was later on corroborated by Burkhardt et al., who speculated that the highly innervated periosteum plays a key role in pain perception and that leaving a greater residual soft tissue thickness was found to reduce pain because the periosteum was less likely to be left exposed to mechanical stimuli. ${ }^{36}$ When performing the single incision technique, Maino et al. found that residual primary flap thickness of $1 \mathrm{~mm}$ or less has a greater probability of secondary wound healing $(\mathrm{OR}=7.67) .{ }^{24}$ Given the importance of having an adequate primary flap thickness $(>1 \mathrm{~mm})^{24}$ and residual soft tissue thickness over the bone for minimize patient morbidity, harvesting a CTG of desired thickness is not always feasible with the TDT or single incision technique. ${ }^{15}$ However, this is not a limitation for the FGGT which can be performed regardless of the thickness of the palatal fibromucosa. ${ }^{15,25}$

Shallow PVH were related to more leakage in the two groups. A correlation between PVH and the course of the greater palatine artery was suggested by previous studies. ${ }^{30,43}$ It is reasonable to assume that when the PVH is shallow, the graft was harvested closer to the palatal midline that might lead to excessive hemorrhage during harvesting. ${ }^{12,15}$ A recent systematic review proposed a safety zone for avoiding the injury of the greater palatine artery and its branches, suggesting that a graft harvested in the premolars and first molar area should not exceed $8 \mathrm{~mm}$ in height. ${ }^{31}$

The amount of blood loss in periodontal and oral surgery has been previously investigated. ${ }^{44-46}$ Some authors quantified blood loss using the cyanmethemoglobin comparison technique, that measures the concentration of hemoglobin in the aspirated blood using a spectrophotometer. ${ }^{44,47}$ However, this method may not account for the blood loss in the gastrointestinal system or the amount that is lost into the tissues. ${ }^{44}$ Other methods of quantifying blood loss include the following: (i) the collection of the liquids from the oral cavity during the surgery and the use of a fructosamine as a marker molecule (absent from saliva and water) ${ }^{46}$; (ii) the collection of blood during the surgery with the operator recording the bleeding and assigning a score every 15 minutes $^{48}$; and (iii) the use of pre-weighted dry sterile gauzes and the calculation of their increase in weight considering the volumes of irrigation solution and ultrasonic scaler. ${ }^{45}$ Regardless of the mode of assessment, these methods provide an estimation of the blood loss during certain procedures and their conclusion should be interpreted with caution. In our cadaver model a standardized amount of betadine solution was injected in the external carotid artery in a constant period of time by a single calibrated operator. Thus, we assessed and quantified the leakage from the donor site though measuring the changes in the weight of the collagen sponge (which was then converted to $\mu \mathrm{L}$ ). Although the present research protocol may vary from the actual clinical scenario, our aim was to construct a model to compare the resultant injury to the palatal vessels between the TD and FGGT harvesting procedures.

Bleeding from the palatal donor site can be divided into intrasurgical/immediate bleeding and post-surgical/delayed bleeding. According to Griffin et al., post-operative bleeding has a greater association to post-surgical trauma and irritation of the donor site than the surgical procedure itself. ${ }^{13}$ Similarly, the protection of the donor site following FGGT 
was shown to be effective in controlling post-operative bleeding from the palate. ${ }^{14}$ Our research was designed to evaluate which harvesting techniques (TDT or FGGT) caused less vascular trauma, and therefore, may result in less immediate bleeding. This aspect holds particular relevance especially in this era, given the increasing number of patients with bleeding disorders and on anticoagulant therapy. ${ }^{49}$ There is no doubt that performing intra-operative measures aimed at reducing intraoperative bleeding can be beneficial. ${ }^{14}$ Our results suggest that performing the FGGT should be preferred over TDT when an increased intrasurgical bleeding may be expected.

The current investigation yields some limitations. The study was performed in donor cadaver heads, and thus, further clinical studies are necessary to validate our findings. Additionally, the injection of the betadine solution in the artery was performed by an operator, which regardless of the pre-calibration, may produce a certain amount of inaccuracy compared to utilizing an automatic pump. Furthermore, although the single incision approach is another common harvesting technique which has also shown advantages compared to TDT, ${ }^{28,50}$ because of the split-mouth nature of the study, a third comparison was not feasible nor necessary as the current investigation merely served as basis for future clinical trials to evaluate and assess several harvesting approaches. Lastly, a comparison between our results in terms of the leakage and the average blood loss calculated in other procedures could not be performed.

\section{5 | CONCLUSIONS}

Within the limitations of the present research, the TDT resulted in a significantly higher leakage than the FGGT with a ratio of 4.18. Similarly, the histology analysis showed a greater number of medium and large vessels in grafts harvested with the TDT. Regardless of the harvesting approach, a shallow PVH positively affected the leakage.

\section{ACKNOWLEDGMENTS}

The authors would like to thank the body donors and their families; Mr. Dean Mueller, coordinator of the Anatomical Donations Program for preparing the specimens; Mrs. Alicia Backer, clinical coordinator; and Ms. Cynthia Lawson, dental assistant, for coordinating this pre-clinical experiment. The authors do not have any financial interests, either directly or indirectly, in the products or information listed in the article.

\section{SOURCE OF FUNDING}

This paper was partially supported by the University of Michigan Periodontal Graduate Student Research Fund.

\section{ORCID}

Lorenzo Tavelli (D) https://orcid.org/0000-0003-4864-3964

Shayan Barootchi (D) https://orcid.org/0000-0002-5347-6577

Hsun-Liang Chan (D) https://orcid.org/0000-0001-5952-0447

Hom-Lay Wang (D) https://orcid.org/0000-0003-4238-1799

\section{REFERENCES}

1. Giannobile WV, Jung RE, Schwarz F, Groups of the 2nd Osteology Foundation Consensus Meeting. Evidence-based knowledge on the aesthetics and maintenance of peri-implant soft tissues: Osteology Foundation Consensus Report Part 1-effects of soft tissue augmentation procedures on the maintenance of peri-implant soft tissue health. Clin Oral Implants Res. 2018;29(suppl 15): 7-10.

2. Cairo F. Periodontal plastic surgery of gingival recessions at single and multiple teeth. Periodontol 2000. 2017;75:296-316.

3. Chambrone L, Pini Prato GP. Clinical insights about the evolution of root coverage procedures: the flap, the graft, and the surgery. $J$ Periodontol. 2018;9:9-15

4. Atieh MA, Alsabeeha N, Tawse-Smith A, Payne AG. Xenogeneic collagen matrix for periodontal plastic surgery procedures: a systematic review and meta-analysis. J Periodontal Res. 2016;51:438452.

5. Bertl K, Melchard M, Pandis N, Muller-Kern M, Stavropoulos A. Soft tissue substitutes in non-root coverage procedures: a systematic review and meta-analysis. Clin Oral Investig. 2017;21: 505-518.

6. Cairo F, Nieri M, Pagliaro U. Efficacy of periodontal plastic surgery procedures in the treatment of localized facial gingival recessions. A systematic review. J Clin Periodontol. 2014;41(suppl 15):S44-S62.

7. Thoma DS, Buranawat B, Hammerle CH, Held U, Jung RE. Efficacy of soft tissue augmentation around dental implants and in partially edentulous areas: a systematic review. J Clin Periodontol. 2014;41(suppl 15):S77-S91.

8. Yu SH, Tseng SC, Wang HL. Classification of soft tissue grafting materials based on biologic principles. Int J Periodontics Restorative Dent. 2018;38:849-854.

9. de Resende DRB, Greghi SLA, Siqueira AF, Benfatti CAM, Damante CA, Ragghianti Zangrando MS. Acellular dermal matrix allograft versus free gingival graft: a histological evaluation and split-mouth randomized clinical trial. Clin Oral Investig. 2018;23(2):539-550

10. Cairo F, Cortellini P, Pilloni A, et al. Clinical efficacy of coronally advanced flap with or without connective tissue graft for the treatment of multiple adjacent gingival recessions in the aesthetic area: a randomized controlled clinical trial. J Clin Periodontol. 2016;43:849-856

11. Lin GH, Chan HL, Wang HL. The significance of keratinized mucosa on implant health: a systematic review. J Periodontol. 2013;84:1755-1767. 
12. Brasher WJ, Rees TD, Boyce WA. Complications of free grafts of masticatory mucosa. J Periodontol. 1975;46:133-138.

13. Griffin TJ, Cheung WS, Zavras AI, Damoulis PD. Postoperative complications following gingival augmentation procedures. J Periodontol. 2006;77:2070-2079.

14. Rossmann JA, Rees TD. A comparative evaluation of hemostatic agents in the management of soft tissue graft donor site bleeding. $J$ Periodontol. 1999;70:1369-1375.

15. Zucchelli G, Mele M, Stefanini M, et al. Patient morbidity and root coverage outcome after subepithelial connective tissue and deepithelialized grafts: a comparative randomized-controlled clinical trial. J Clin Periodontol. 2010;37:728-738.

16. Tavelli L, Ravida A, Saleh MHA, et al. Pain perception following epithelialized gingival graft harvesting: a randomized clinical trial. Clin Oral Investig. 2018;23(1):459-468

17. Nabers JM. Free gingival grafts. Periodontics. 1966;4:243-245.

18. Edel A. Clinical evaluation of free connective tissue grafts used to increase the width of keratinised gingiva. J Clin Periodontol. 1974;1:185-196

19. Langer B, Langer L. Subepithelial connective tissue graft technique for root coverage. J Periodontol. 1985;56:715-720.

20. Harris RJ. A comparison of two techniques for obtaining a connective tissue graft from the palate. Int J Periodontics Restorative Dent. 1997;17:260-271.

21. Bruno JF. Connective tissue graft technique assuring wide root coverage. Int J Periodontics Restorative Dent. 1994;14:126-137.

22. Hurzeler MB, Weng D. A single-incision technique to harvest subepithelial connective tissue grafts from the palate. Int J Periodontics Restorative Dent. 1999;19:279-287.

23. Lorenzana ER, Allen EP. The single-incision palatal harvest technique: a strategy for esthetics and patient comfort. Int J Periodontics Restorative Dent. 2000;20:297-305.

24. Maino GNE, Valles C, Santos A, Pascual A, Esquinas C, Nart J. Influence of suturing technique on wound healing and patient morbidity after connective tissue harvesting. A randomized clinical trial. J Clin Periodontol. 2018;45:977-985.

25. Zucchelli G, Mounssif I. Periodontal plastic surgery. Periodontol 2000. 2015;68:333-368

26. Bertl K, Pifl M, Hirtler L, et al. Relative composition of fibrous connective and fatty/glandular tissue in connective tissue grafts depends on the harvesting technique but not the donor site of the hard palate. J Periodontol. 2015;86:1331-1339.

27. Romano F, Perotto S, Cricenti L, Gotti S, Aimetti M. Epithelial inclusions following a bilaminar root coverage procedure with a subepithelial connective tissue graft: a histologic and clinical study. Int J Periodontics Restorative Dent. 2017;37: e245-e252.

28. Del Pizzo M, Modica F, Bethaz N, Priotto P, Romagnoli R. The connective tissue graft: a comparative clinical evaluation of wound healing at the palatal donor site. A preliminary study. J Clin Periodontol. 2002;29:848-854.

29. Keskiner I, Aydogdu A, Balli U, Kaleli AE. Quantitative changes in palatal donor site thickness after free gingival graft harvesting: a pilot study. J Clin Periodontol. 2016;43:976-984.

30. Fu JH, Hasso DG, Yeh CY, Leong DJ, Chan HL, Wang HL. The accuracy of identifying the greater palatine neurovascular bundle: a cadaver study. J Periodontol. 2011;82:1000-1006.

31. Tavelli L, Barootchi S, Ravida A, Oh TJ, Wang HL. What is the safety zone for palatal soft tissue graft harvesting based on the locations of the greater palatine artery and foramen? A systematic review. J Oral Maxillofac Surg. 2018;77(2):271

32. Klosek SK, Rungruang T. Anatomical study of the greater palatine artery and related structures of the palatal vault: considerations for palate as the subepithelial connective tissue graft donor site. Surg Radiol Anat. 2009;31:245-250.

33. Caraballo J, Galvez A, Manzanares-Cespedes MC, ValdiviaGandur I, Figueiredo R, Valmaseda-Castellon E. Vascular structures of the lateral wall of the maxillary sinus: a vascular labeling technique. Implant Dent. 2017;26:153-157.

34. Schneider CA, Rasband WS, Eliceiri KW. NIH image to ImageJ: 25 years of image analysis. Nat Methods. 2012;9:671-675.

35. Wessel JR, Tatakis DN. Patient outcomes following subepithelial connective tissue graft and free gingival graft procedures. $J$ Periodontol. 2008;79:425-430.

36. Burkhardt R, Hammerle CH, Lang NP, Research Group on Oral Soft Tissue Biology \& Wound Healing. Self-reported pain perception of patients after mucosal graft harvesting in the palatal area. $J$ Clin Periodontol. 2015;42:281-287.

37. Tavelli L, Asa'ad F, Acunzo R, Pagni G, Consonni D, Rasperini G. Minimizing patient morbidity following palatal gingival harvesting: a randomized controlled clinical study. Int J Periodontics Restorative Dent. 2018;38:e127-e134.

38. Yildirim S, Ozener HO, Dogan B, Kuru B. Effect of topicallyapplied hyaluronic-acid on pain and palatal epithelial wound healing: an examiner-blind, randomized, controlled clinical trial. J Periodontol. 2017:1-14.

39. Keceli HG, Aylikci BU, Koseoglu S, Dolgun A. Evaluation of palatal donor site haemostasis and wound healing after free gingival graft surgery. J Clin Periodontol. 2015;42:582-589.

40. Zuhr O, Baumer D, Hurzeler M. The addition of soft tissue replacement grafts in plastic periodontal and implant surgery: critical elements in design and execution. J Clin Periodontol. 2014;41(suppl 15):S123-S142.

41. Chan HL, Wang HL, Fowlkes JB, Giannobile WV, Kripfgans OD. Non-ionizing real-time ultrasonography in implant and oral surgery: a feasibility study. Clin Oral Implants Res. 2017;28: 341-347.

42. Tavelli L, Barootchi S, Ravida A, Suarez-Lopez Del Amo F, Rasperini G, Wang HL. Influence of suturing technique on marginal flap stability following coronally advanced flap: a cadaver study. Clin Oral Investig. 2018;23(4):1641-1651

43. Reiser GM, Bruno JF, Mahan PE, Larkin LH. The subepithelial connective tissue graft palatal donor site: anatomic considerations for surgeons. Int J Periodontics Restorative Dent. 1996;16: 130-137.

44. Baab DA, Ammons WF, Jr., Selipsky H. Blood loss during periodontal flap surgery. J Periodontol. 1977;48:693-698.

45. Moore PA, Doll B, Delie RA, et al. Hemostatic and anesthetic efficacy of 4\% articaine $\mathrm{HCl}$ with 1:200,000 epinephrine and $4 \%$ articaine $\mathrm{HCl}$ with 1:100,000 epinephrine when administered intraorally for periodontal surgery. J Periodontol. 2007;78: 247-253.

46. Zigdon H, Levin L, Filatov M, Oettinger-Barak O, Machtei EE. Intraoperative bleeding during open flap debridement and regenerative periodontal surgery. J Periodontol. 2012;83: 55-60.

47. Berdon JK. Blood loss during gingival surgery. J Periodontol. 1965;36:102-107. 
48. Braganza A, Bissada N, Hatch C, Ficara A. The effect of nonsteroidal anti-inflammatory drugs on bleeding during periodontal surgery. J Periodontol. 2005;76:1154-1160.

49. Vassilopoulos P, Palcanis K. Bleeding disorders and periodontology. Periodontol 2000. 2007;44:211-223.

50. Fickl S, Fischer KR, Jockel-Schneider Y, Stappert CF, Schlagenhauf U, Kebschull M. Early wound healing and patient morbidity after single-incision vs. trap-door graft harvesting from the palatea clinical study. Clin Oral Investig. 2014;18:2213-2219.
How to cite this article: Tavelli L, Barootchi S, Namazi SS, et al. The influence of palatal harvesting technique on the donor site vascular injury: A split-mouth comparative cadaver study. J Periodontol. 2020;91:83-92. https://doi.org/10.1002/JPER.19-0073 